Journal of Social Sciences (COES\&RJ-JSS)

ISSN (E): 2305-9249 ISSN (P): 2305-9494

Publisher: Centre of Excellence for Scientific \& Research Journalism, COES\&RJ LLC

Online Publication Date: $1^{\text {st }}$ July 2017

Online Issue: Volume 6, Number 3, July 2017

https://doi.org/10.25255/jss.2017.6.3.656.665

\title{
The Role of Total Quality Control (TQC) in the Technical
}

\author{
Dr. Sana'a Nawaf Al-Nsour ${ }^{1}$, Ahmad Ali Khalefah Al-Zoubi \\ Dr. Bilal Ali Yaseen Al-Nassar ${ }^{1}$, Dr. Feras Ali Alzu'bi ${ }^{1}$ \\ ${ }^{1}$ The World Islamic Sciences and Education University (WISE), Amman, Jordan \\ ${ }^{2}$ Al-Balqa Applied University (BAU), Jordan
}

\begin{abstract}
:
In the current times, quality is the key word in industries, government and public agencies, often in the concept of total quality or total quality control. The proliferation of Total Quality Control (TQC) has produced a debate. The debate lies between the argument of TQC advocates, who consider it as a distinct and effective method to improve organizational performance, and those who just consider it as another organizational fad. The controversial debate pits TQM advocates against expert scholars who are wellinformed of the TQC root methods. More specifically, TQC advocates make use of TQC to develop a position upon which they can scrutinize academic work by failing to examine the concept thoroughly despite the fact that academicians should be able to understand the concept deeply more than advocates, as TQC makes use of technical methods that scholars have been examining for many years. The aim of the present study was to arrive at the common TQC understanding in the technical.
\end{abstract}

Keywords:

Total Quality Control, Quality Control, Total Productive Maintenance, Technical.

Citation:

Al-Nsour, Dr. Sana'a Nawaf ; Al-Zoubi, Ahmad Ali Khalefah ; Al-Nassar, Dr. Bilal Ali Yaseen ; Alzu'bi , Dr. Feras Ali (2017); The role of Total Quality Control (TQC) in the technical; Journal of Social Sciences (COES\&RJ-JSS), Vol.6, No.3, pp:656-665; https://doi.org/10.25255/jss.2017.6.3.656.665. 


\section{Introduction}

In the current times of commercial activities rife with competition and devoid of borders, firms have to consistently improve their performance towards enhancing their productivity, quality and delivery. In the dynamic and technologically driven markets, firm should not depend on a few fundamental skills to develop and survive. They have to exert effort to create a group of core competencies (Prahalad\& Hamel, 1990) in order to establish a well-balanced business operation.

Successful organizations have been noted to employ improvement programs on the basis of a management paradigm like total quality control (TQC), total quality management (TQM) that originates from the initial just-in-time paradigm (JIT). Moreover, total productive maintenance (TPM) has increasingly spread throughout different countries around the world. However, the concepts and methods adoption obtained from one paradigm may not be as effective in producing improvements and innovations that are needed in the present market to guarantee business survival and growth. In the present paper, the researcher promotes the merits of the adoption of a combined approach in an effort to develop the expansive set of organizational capabilities that organizations are required to have to establish well-balanced businesses.

After the Second World War, the quality control movement began in Japan and has become successful as one of the main factors that propelled Japan as one of the world leaders in the manufacturing production processes. Towards the 1970s, Japan successfully went head to head with the major industrialized countries following its rapid recovery from the Oil Crises of the 1970s, with other industrial countries remaining in limbo and wondering at Japan's secrets of success. In the continuous de-industrialization of the U.S., the industrial restructuring of Australia, faced by the global economic pressures, the Japanese way of using quality programs were extensively viewed as the solution to the perceived loss of industrial competitiveness. Nevertheless, the successful launching and adoption of Japanese methods in the West as total quality management (TQM), and it has retained its position as a highly debatable and contentious issue, receiving both praise and criticism for its failure (Basu, 2001).

The present paper is organized in the following way for easy understanding; Section 1 contains the introduction of the paper section 2 provides the overview of quality control. This is followed by section 3 that contains a comparison between TQC and TPM paradigms. In section 4, the paper provides a description of the training programs of quality control and total quality control, while section 5 details TQC and technical aspects. Lastly, section 6 contains recommendations for future work.

\section{Overview of Quality Control}

In 1943, Bridgestone launched the statistical methods of quality control and by 1952 , following the establishment of Japan Union of Scientists and Engineers (JUSE), the employees started taking part in Quality Control (QC) seminars. By 1957, QC Sections were set up at the plant level, and in 1964, TQC was launched under the Deming Plan Activities - a plan for pursing extensive organizational improvement (taishitsu kaizen) and to shift from management by the founder to organization-based management. After four years, Bridgestone obtained Japan's premier quality prize in 1968, the Deming Prize. The following year, Bridgestone introduced an extensive IE (Industrial Engineering) program throughout the company and Mandel, an IE expert from the U.S. was invited to give a 
lecture at the company along with two American QC experts Juran and Deming, in 1969 and 1970 respectively. IE training courses were also initiated and expanded by the mid1970s through the addition of advanced, specialized courses and supported by improvement technique courses on a group-wide basis, in collaboration with other companies in the 1980s.

Following the above developments, 1982 heralded the launching of the Deming Plan Renewal that concentrated on the integration of quality control activities as a part of dayto-day work. In addition, a campaign that advocated to half inventory was adopted in preparation of introducing the TPM program in 1986. This is followed by the introduction of the Zero Quality Defects (QZD) program in 1988, which coincided with the $20^{\text {th }}$ anniversary of the company that worn the Deming Prize. In 1994, the P150 campaign was introduced - a company extensive effort that worked towards enhancing productivity by $50 \%$ over three years. However, the perceived negative effects of concentrating solely on productivity led to the renaming of the campaigning to PQS150, with (P) standing for productivity (gains to be anchored with maintenance/improvement of quality (Q) and standards of safety $(\mathrm{S})$.

In 1994, the Hikone Plant became the first Japanese plantthat were ISO9002 accredited but the plants use of the QC/TQC consultant was maintained twice yearly (Dale, 1991). This was attributed to the argument that the high level of QA/QC activities were difficult to maintain by depending on the factory's own resources and thus, a consultant's support and advice were valuable. Managers, foremen, supervisors, and engineering staff attended the meetings and novel programs were introduced, while old ones were made obsolete. Following the TQC adoption in 1964, the company launched IE in 1969, followed by TPM in 1986 and the programs were implemented aligned with new and old programs, supplemented by training programs that were extended and upgraded over the years.

Through the years, the Hikone Plant became the recipient of the Director of the Trade and Industry Bureau's Prize, the Director of the Industrial Science and Technology Agency Prize and the Minister's prize for Excellence in the Industrial Standardization, in 1985, 1988 and 1992 respectively. In 1990, the factory also received the Japan Plant Maintenance Association Prize (Barnett, 1991).

In the ensuing years, particularly, mid-1996, the factory made a TQM declaration and adopted activities to support management's exploitation of the knowledge and technical capability gathered in the prior TQC phase and by 1998, it inaugurated TQM activities as the TQM Promotion Office introduced the SZD Renaissance initiative to leverage the strengths and rectify the weaknesses of the prior initiatives undergone from 1988-1992. The corporate TQM Promotion Office (TQM Shuishinshitsu) published a 54 paged SZD Renaissance Guide and by 2000, another significant review and update of QA procedures and documentation was conducted. In 2001, Action QS21, under the subtitle Quality Spiral-Up Program, included all workers from the Technical Center and from the factories. On the basis of process improvement that advocates the achievement of quality improvement, the program primarily concentrated on the reformation of attitudes, enhancement of work techniques, and adopting and using tools required for the optimization of the company processes. 


\section{TQC and TPM Paradigms}

With the popularity and extended use of TQC and TPM paradigms throughout different industries, the comparison between the two has been explored throughout the years. For instance, Miyake and Enkawa (1997a) noted that the two paradigms co-existence has led to the controversial premise that one is redundant or against the other, and hence, they may have mutual exclusivity.

Other related studies like Senju (1988, 1989, 1992), Akaoka (1992) and Ogake (1995) conducted an analysis of the TQC and TPM characteristics by comparing their relative strengths and weaknesses. According to the authors, the combined approaches work towards attaining improved overall performance as they complement each other. Moreover, the characteristic features of each were highlighted in general terms rather than in explicit analytical structure.

Furthermore, Kato (1988), Kouchi (1988), Takada (1988), Ikezawa, Ozawa, Oyaizu and Nohmaru (1989), Katsuta (1989), Munekata (1989), Ohwada (1989), Oochi (1990), Sugaya (1990) and Yokomatsu (1990) are other studies that examined the theme, within which they brought out actual evidence from practitioners who attempted to combine the two approaches in Japanese manufacturing plants.

In more recent studies, the use of analogous strategies by Japanese manufacturers was examined like Harris Ireland (McAdam\&Duffner, 1996), Waterville TG Inc. in Canada (Bea, 1995) and of Brazil (Mirshawka, 1997). These studies indicate that alignment between TQC and TPM as an arising trend among the various industries throughout the globe. Nevertheless, the studies limitations lie in their demonstration of single cases in a narrative manner, indicating the lack of a structured comparative discussion of the paradigms and a clear elucidation.

This work intends to fill the gap in literature by developing a structured comparative analysis of the two paradigms in terms of qualitative and functional dimensions. This necessitated the design of a frame of comparison to provide an overview of each subject paradigm. The dimensions adopted in the frame include direction, domain, communication, assurance of quality, management style, methodology, improvement approach, diagnostic strategy, design and human resources. Each of the above mentioned criterion was divided into objective sub-dimensions that could characterize both TQC and TPM contents.

Therefore, both TQC and TPM were analyzed by highlighting their characteristic features after which such features were noted and consolidated with the insights provided by Enkawa (1995a), Miyake, Enkawa and Fleury (1995) and Miyake and Enkawa (1997a). The features were revised and synthesized based on the frame developed to obtain the constitutions of both paradigms, along with their similar and resembling issues.

In doing so, the aspects and approaches obtained from each one were pitted against the elements of the other and it indicated that the concurrent use of both could lead to the following;

1. The use of both TQC and TPM is based on some similar objectives, with none of each of the paradigm's features overpowering the other in light achievement. Each of them is more powerful in the pursuit of both. In relation to this, the sufficiency of the relative 
strength to the firm's needs may differ as time passes and therefore, the use of both allows their strengths to be leveraged, achieving a maintained enhancement of firm competitiveness.

2. Exclusive elements have also been noted in both paradigms that drive the achievement of distinct objectives. Therefore, their combined use could develop combined set of capabilities that is extensive compared to the set focused by individual paradigms. Therefore, the combined use of both allows a more extensive competitive pattern.

\section{Training Programs of Quality Control and TQC}

In Japan, a significant part of quality control is evidently the expansive utilization of QC training courses that forms a part of more general in-house training programs. In this regard, training is provided throughout the tenure of the employees in the company, with most of them hired following their graduation from school/universities and they stay until retirement. The courses focused on distinct employees that are evaluated based on difficulty level of training (Ishikawa, 1989). Training includes training in quality control, coupled with an extensive array of courses that are focused on specific employee category, after which they obtain grades based on the difficulty level.

According to Ishikawa (1989), all employees should know statistical methods and hedistinguished between three main education levels and training (i.e., basic, intermediate and advanced). More specifically, basic courses are provided to top and middle management and operators for the creation and understanding of the QC importance and fundamental understanding of the seven QC tools. On the other hand, intermediate courses are provided to engineering workers and young assistant managers in operations, and lastly, advanced courses are for selected specialist engineers and QC engineers. In each level, it is assumed that the employee has mastered the preceding levels content. Ishikawa (1989) also distinguished among eight employees' categories based on quality related training purposes.

Similarly, other Japanese researchers also emphasized on the importance of focusing on and grading QC training courses. More specifically, Mizuno explained education and training and its relationship to six groups of employees namely, top management middle management and staff, QC staff, operators, administration/office staff, and R\&D staff. Despite their grouping together, the authors distinguished between the courses content for middle management and general engineering staff. For middle management, Mizuno included the quality control concept, control charts (less than $10 \%$ of the appropriated time), statistical methods ( $15 \%$ of time), and the QC implementation (over half of the appropriated time). And for general engineering staff, along with the above mentioned four contents, Mizuno mentioned statistical methods testing, estimation, correlation analysis and variance analysis, along with a fifth content, which is analysis and experimentation.

Meanwhile, Asaka (1988) made a distinction between four employee groups based on education and training in different development stages of QC system namely, introduction, development and consolidation. As for the employee groups, they are four in number; top/senior management, specialists, first-line supervisors and operators. He proceeded to provide examples of course content for the second and third groups, wherein which statistical methods and technical content are stressed. 
Furthermore, in-house training is reinforced by various courses provided by different entities including, Japan Union of Scientists and Engineers (JUSE), Japan Standards Association (JSA), Japan Management Association (JMA), and Japan Productivity Center (JPC). Similar with in-house training programs, the courses are provided based on level of difficulty and relevance to the employee categories. Several conferences, symposia and seminars, both at regional and national level, are also held to provide exchange and dissemination of QC information and learning. Added to this, different professional journals also play a key role in education and training at the individual level.

More importantly, QC provided training courses have to be considered on the basis of an extensive in-house program of training courses catering to the acquisition and honing of job skills and management skills. In this regard, graded courses of technical scales are provided to workers at each career phase, with some provided compulsorily and others optional (Ishikawa, 1989). Aside from the scheduled training programs, specific training courses are organized and provided aligned to the launching of novel methods/machinery/equipment. Courses concerning management responsibilities and techniques are provided to newly appointed management prior to occupying their positions.

With regards to engineering staff, QC training appeared to be ad-hoc and haphazardly provided. The quality-related staff was provided with a course in quality engineering or the introductory course in QS9000, or similar training programs. It appeared that the technical service staff was not as likely to be exposed to quality control courses. One interviewee related that training staff depend on QC people to be completely trained and that owing to the close work between TS and Quality Assurance (QA), TS staff had a tendency to be exposed to the fundamental quality theory in order to be aware of the principles it involves. Some years earlier, during the heavy promotion of quality, everybody was exposed to courses but this was not enough to provide TS staff more than the basics that they picked up while working with QA staff. Moving on to engineering staff, it was unclear whether or not they were provided with organized training. Quality related training generally meant quality circle training and other groups of employees were trained on a simpler form of circle training. There was lack of systematic plan in providing supplementary courses for those who were recipients of initial training in 1993, and lack of provision of quality or quality circle for the new recruits.

\section{TQC and the Technical .}

QC approach among the Japanese companies is extensive and it calls for quality to be considered at each manufacturing stage ranging from product development and design, to purchasing materials (relationships with suppliers), engineering of production processes, production, maintenance, sales and service and tackling complaints and returns of products. Any weakness or fault in the system may backfire and manifest in the operation stages, and as such, quality is only as strong as the weakest link in the chain.

However, the Japanese objective behind quality control was clearly to improve product quality, with pursuit to enhance production process/system. The other company's operational aspects were important in as far as they influence in achieving this aim. For instance, according to Mizuno, administration and management should take part in QC although often times, they focus on enhancing their own areas, steering clear of carrying 
out considerable work in ensuring product quality - they merely provide documentation of manufacturing standards or develop HR needed to guarantee quality (Mann, 1992).

Stated clearly, the role of non-production departments, like administration go only as far as facilitating and supporting or sometimes, impeding production work - the focus is not directed on their own business processes, with the exception of process change that would bring about production of work.

Japanese do not pursue quality control in its exclusivity from other management objectives (e.g., cost, meeting production schedules/productivity) rather the Japanese authors indicated that the product itself narrowly defines quality, whereas the integration of quality, cost and delivery/time management (QCD) is the more general definition of it (Ishikawa, 1989).

Additionally, quality control and the production system, specifically the process control (Kozo, 1990) is deemed to be interconnected and interdependent processes. For instance, Mizuno claimed that quality encapsulates the physical and chemical properties of the product along with the quality aspects linked with cost (yield, unit cost and rate of operation). This indicates that the quality definition covers elements often deemed to be forming process control.

Process control is defined by the Japan Management Association as the manufacturing of products of a specific quality and quantity at a certain date (Tasugi\& Mori, 1960, cited by Kozo, 1990). Conversely, process control covers quality and this relationship is not a complex one, explained by Kenji (2005) as the moving from inspecting out defective products to building in quality, following that the production process has to have the capability of delivering the expected quality.

Process analysis and control aims were clear in the work of key authors in the Japanese movement. For instance, Ishikawa (1989) devoted two chapters to process analysis and improvement and process control, involving more than just statistical process control or the in or out of control of the process. Ishikawa (1989) further elaborated that the process capability study is the fundamental platform upon which quality control is built on. He stated that the quality determination and design, and process design planning and control or management of machinery and equipment, process control and improvement, referred to as the quality control processes, would be impossible if devoid of a thorough, robust knowledge on process capability, upon which the present actual operating performance of organizations is based (Hashimoto, Juro, Hasegawa \& Hideaki, 2005).

This was supported by Mizuno, Chou and Inouye (1984) and Skinner (1988) who elaborated on process analysis and process planning, control and improvement. Meanwhile, Asaka1988, provided the collection and collation of data, correlation, process analysis, experiments design, inspection and quality assurance with robust statistical content, while Mizuno 1994, focused on quality control aspects relating to senior and middle management role, and the activities of QC in different departments, with specific focus on organizational planning.

Mizuno et al. (1984) also focused on issues concerning quality control allocation of responsibilities across the organization, policy deployment and management control as opposed to abstract leadership notions. They laid emphasis on statistical analysis and 
refuted the premise that statistical quality control (SQC) is obsolete and TQC has replaced it.

According to them, there are some cases with the administration work involving only the preparation of documents and paper work, devoid of any analysis and other issues that require statistical techniques based on the shift from statistical quality control to TQC. The use of such statistical methods however, is still significant in TQC (Mizuno et al., 1984). In the recession year of 1991, the Hikone plant was the host of the company's global Deming Plan Presentation Meeting that was attended by quality teams around the globe. By 1992, the Federal Government's Best Practice Workplace Reform program was utilized to recruit consultants to assist in developing self-managed work teams. Only one remained in operation by 1996 despite the attempt to launch such teams. When the plant was only in operation 4 days a week in 1993, workers got paid full due, with Fridays used for quality concept training. Tools and their practical applications were introduced in quality circle activities. However, the peak of quality circle activities declined from over 20 circles in 1995 to 7 circles towards the end of 1995 , and only 2 by the middle of 1996 .

Although such difficulties arose, the plant still maintained a good successful record in its pursuit of quality accreditation and activities. The company was the recipient of Ford Q101 rating in 1989, and Ford Q1 rating in 1990, and the plant was awarded an A rating by the United Australian Automotive Industries (Sohal, Samson \& Ramsay, 1994), and it received the Toyota Supplier of the Year Award. Finally, in 1993, it was accredited with AS3901/ISO9001, making it Bridgestone's worldwide operation to do so. After being the recipient of the Certificate of Merit in 1993, it won the industry award, FCAI Supplier of the Year Award in 1994 (Schonfeld, Sheehan \& Steinhardt, 2005).

The plant conducted major upgrades to its quality system in 1996 in order to meet the QS9000 accreditation criteria and at the same time, it was in pursuant of the P150 program that was a global program adopted by the parent company to enhance productivity by $50 \%$ in every facility over three years (1995-1997). It received its QS9000 accreditation by 1997, and it became the first plain in its industry in Australia to be so, similar to being the first of the company's worldwide operation to obtain ISO9001. From the reviewed Australian case studies, this company appeared to be the most advanced in light of practical, operating quality system.

\section{Conclusion}

TQC is entirely using common sense and transforming it into practice as the Japanese did. They managed common sense, forced it and implemented it systematically. A western saying states that common sense cannot be taught, and the Japanese that just proved it wrong. In terms of TQC, nothing new and revolutionary was discussed, but the difference lies in the fact that the West talks about TQC, while the Japanese practice it. Successful Japanese companies may not only be attributed to their technology, sophisticated equipment, work methods and rate of work.

It is important that for an organization to improve its performance and competitiveness, it should concentrated on production technology advances and improvement of product quality. In other words, the competitiveness of businesses largely hinges on whether or not it can provide superior quality/services, and in relation to this, Chinese enterprises have several weaknesses. This necessitates the need to develop and set up a scientific, rational and effective quality management system and to boost TQC implementation. Management 
should be centered on people and a scientific way of managing in using mathematical statistical methods in order to realize a combination of anti-inspection.

\section{References}

Akaoka, J. (1992) TPM to TQCÐ TPM nisenkou shite mazu TQC nitorikumukotowayuueki (TPM and TQCĐ introducing TQC before TPM), Standardization and Quality Control, 45, pp. 84 - 90.

Barnett, N.S. (1991) "Management and Statistical Issues Affecting Quality Improvement in Australia."International Journal of Quality and Reliability Management, 8 (5), pp. 913.

Basu, R. (2001) "Six Sigma to Fit Sigma", IIE Solutions, July. pp. 29-33.

Beâ lair, D. (1995) Japanese plant culture in a Canadian company through TPM.Proceedings of '95 TPM World Congress, Tokyo, Japan Institute of Plant Maintenance, pp. C1.2.1- C1.2.11.

Dale, B.G. and Tidd, J. (1991) "Japanese Total Quality Control: A Study of Best Practice." Proceedings of the Institution of Mechanical Engineers and Part B. Journal of Engineering Manufacture, 205, pp. 221-232.

Enkawa, T. (1995a) TQC gachokumensuruyottsu no kadai Four issues which are faced by TQC), Standardization and Quality Control, 48, pp. 19 - 25.

Hashimoto, Juro, Shin Hasegawa and Hideaki Miyajima (2007) Gendai Nihon keizai(The Contemporary Japanese Economy) (2nd edn). YuhikakuAruma, Tokyo.

Ikezawa, T., Ozawa, M., Oyaizu, M. \&Nohmaru, I. (1989). TQC niokeru TPM no ichizuke (Placement of the TPM activities in TQC activities), Standardization and Quality Control 40, pp. 35 - 42.

Ishikawa,A (1989). Introduction to Quality Control (3rd Edition), 3A Corporation.

Kato, N. (1988) Yoriyoishitsuwoyoriyasuku, yorihayaku (Better good, more inexpensively and more speedily), Standardization and Quality Control, 41, pp. 16- 24.

Katsuta, M. (1989) Kansai Nihon Denki no TPM katsudou: TQC no ikkan to shite no tenkai (TPM activities at NEC Kansai: a program on TQC promotion), Standardization and Quality Control, 40, pp. 17- 23.

Kouchi, K. (1988) TPM de cosutodoun no kyokugennichousen (Aim the limit of cost reduction through TPM), Standardization and Quality Control, 41, pp. 10-15.

Koura, Kozo (1990) "Demingusakurukarakanri no sakuru e" (From the Deming Circle to the management circle." Hinshitsu (Quality), 20 (1), January. pp. 37-47.

Kurogane, Kenji (2005) Hinshitsukanrinyumon(Introduction to Quality Control). Japan Standards Association, Tokyo.

Mann, R.S. (1992) The Development of a Framework to Assist in the Implementation of Total Quality Management.Unpublished PhD Thesis.University of Liverpool, Liverpool. Mcadam, R. \&Duffner, A.M. (1996) Implementation of total productive maintenance in support of an established total quality programme, Total Quality Management, 7, pp. 613 630.

Mirshawka, V. (1997) ExceleÃnciaempresarialatravêิA s da qualidade (Corporate excellence through quality), Qualimetria, 9, pp. 3- 7.

Miyake, D.I. \&Enkawa, T. (1997a) Guidelines to nurturing well-balanced manufacturers through complementary application of TQC and TPM, unpublished Technical Report 972, Tokyo Institute of Technology, Tokyo.

Miyake, D.I., Enkawa, T. \&Fleury, A.C.C. (1995) Improving manufacturing systems performance by complementary application of just-in-time, total quality control and total productive maintenance paradigms, Total Quality Management, 6, pp. 345-363. 
Mizuno, T., Chou, M. Y., \& Inouye, M. (1984). A unique mechanism regulating gene expression: translational inhibition by a complementary RNA transcript (micRNA). Proceedings of the National Academy of Sciences, 81(7).

Munekata, K. (1989) Toyoda Kouiniokeru TQC-TPM katsudou (TQC and TPM activities at Toyoda Machine Works), , 40, pp. 11 - 16.

Ogake, H. (1995) TQC to TPM no tokushitsuwoikashitasetsubikanri (Equipment control utilizing the characteristics of TQC and TPM), Standardization and Quality Control, 48, pp. $81-89$.

Ohwada, Y. (1989) Nagano Jeco no jishuhozenkatsudou: zen-in sanka de eta PM shou (TPM activities in Nagano Jeco), HinshitsuHanri, 40, pp. 25-33.

Oochi, K. (1990) TQC to TPM (TQC and TPM), Standardization and Quality Control, 43, pp. 28 - 36.

PRAHALAD, C.K. \& HAMEL, G. (1990) The core competence of the organization, Harvard Business Review, 68, pp. 79- 91.

Schonfeld, C. C., Sheehan, M. C., \& Steinhardt, D. A. (2005). A content analysis of Australian motor vehicle advertising: Effects of the 2002 voluntary code on restricting the use of unsafe driving themes.

Senju, S. (1988) TQC to TPM (TQC and TPM), Standardization and Quality Control, 41, pp. 4- 9.

Senju, S. (1989) TQC to TPM (TQC and TPM), HinshitsuKanri, 40, pp. 6- 10.

Senju, S. (1992) TQC and TPM (Tokyo, Asian Productivity Organization),(3Ed.).

Shiomi, H. (1990) TQC to TPM no kihontekikangaekatasusumekata (Fundamental concepts of TQC \& TPM and promotion for their activities), Standardization and Quality Control, 43, pp. 5 - 11.

Skinner, W. (1969) "Manufacturing: Missing Link in Corporate Strategy." Harvard Business Review, 47 (May-June), pp. 136-145.

Sohal, A. S., Samson, D., \& Ramsay, L. (1994). Toyota Moto Corporation Australia: a case study. Total Quality Management, 5(6), 431-440.

Sugaya, K. (1990) Saikou no hinshitsuwosaitei no kosuto de (Creating the highest quality at the lowest cost), Standardization and Quality Control, 43, pp. 22-27.

Takada, K. (1988) TPM de moukarukoujoutaishitsu he kakushin (Renovation into lucrative factory constitution), Standardization and Quality Control, 41, pp. 25- 33.

Tasugi, H., \& Mori, K. (1960). On the influence of trace elements on disease resistance. I. On the rice blast and the Helminthosporium of the sixtieth Birth days of prof. YosihikoTochinai and prof. TerikuchiFukushi, 57-64.

YOKOMATSU, H. (1990) Nissan Jidoushaniokeru TPM katsudou (TPM in Nissan and its future), Standardization and Quality Control, 43, pp. 12-21. 